\title{
Pillbox Use and INR Stability in a Prospective Cohort of New Warfarin Users
}

Stephanie Dumas, BSc; Etienne Rouleau-Mailloux, MSc; Nawal Bouchama, BSc; Halema Lahcene, BSc; Mario Talajic, MD, FRCPC, FACC; Jean-Claude Tardif, MD, FRCPC, FACC, FCAHS; Marie-José Gaulin, BSc; Sylvie Provost, MSc; Marie-Pierre Dubé, PhD; and Sylvie Perreault, BPharm, PhD

\section{ABSTRACT}

BACKGROUND: Warfarin, a frequently prescribed oral anticoagulant, is well known for its narrow therapeutic index. Adherence to warfarin may help to achieve a stable international normalized ratio (INR), but little data are available regarding the impact of using a pillbox as a potential adherence aid device.

OBJECTIVE: To evaluate the association between pillbox use and time in therapeutic range (TTR) $<60 \%$ and INR instability pattern.

METHODS: This study was based on a prospective cohort of 1,069 new warfarin users who initiated warfarin between May 2010 and July 2013 within 17 hospitals in Quebec, Canada. Demographic, lifestyle, and clinical data were collected for 3 months to a year after warfarin initiation, and genetic factors were assessed. Patients usingh self-prepared and pharmacist-prepared pillboxes were compared with nonusers for the 3- to 12-month follow-up period. The primary outcome was a TTR $<60 \%$, which represents a low percentage of time in the INR therapeutic range or an unstable patient. The secondary outcome was the INR instability pattern (unstable below range; unstable over range; unstable with erratic pattern; and stable) to better describe patient INR profiles. A multivariate generalized linear mixed model was used for the primary outcome, along with a multivariate multinomial linear mixed model for the secondary outcome.

RESULTS: The cohort included patients with a mean age of $70.4 \pm 11.7$ years; $61.8 \%$ of patients were men; $76.3 \%$ had atrial fibrillation as warfarin's primary indication; and $35.6 \%$ had a previous history of myocardial infarction or angina. Self-prepared and pharmacist-prepared pillbox use was not associated with TTR $<60 \%$ or a specific INR instability pattern. A sensitivity analysis showed that self-prepared pillbox users had a higher TTR than nonusers $(3.55 \% \pm 1.69 \% ; P=0.036)$. This effect was greater among patients aged $<70$ years $(5.48 \% \pm 2.50 \% ; P=0.029)$ than among older patients $(1.92 \% \pm 2.31 \% ; P=0.406)$.

CONCLUSIONS: Pillbox use was not associated with TTR $<60 \%$ or a specific INR instability pattern. The impact of self-prepared pillbox use was greater among younger patients, but results were not clinically significant. Future studies adjusting for concomitant drug use are needed to clarify these results.

J Manag Care Spec Pharm. 2016;22(6):676-84

Copyright $\odot 2016$, Academy of Managed Care Pharmacy. All rights reserved.

\section{What is already known about this subject}

Adherence to warfarin is a key factor involved in the achievement of a therapeutic and stable international normalized ratio (INR), but little is known about the potential benefits of pillbox use. Pillbox use has been proven to help patients achieve a higher level of adherence in other therapeutic areas.

\section{What this study adds}

This study reported that pillbox use in a real clinical setting was not associated with INR stability.

Patients aged $<70$ years who used a self-prepared pillbox achieved a greater INR stability than older users, but this finding was not clinically significant.

$\mathrm{D}$ espite the addition of new oral anticoagulants on the market, warfarin remains a frequently prescribed drug to prevent thromboembolic events. ${ }^{1}$ However, warfarin's narrow therapeutic index is still an ongoing challenge for clinicians and patients. Multiple blood tests and dosage adjustments are required for patients to achieve an international normalized ratio (INR) within the targeted therapeutic range, defined according to a patient's indication. A subtle change in a patient's clinical profile and behaviors, such as adherence, can have a large impact on warfarin's effectiveness and safety.

As reported in the literature, patients who are taking warfarin and whose INR target range is between 2 and 3 have an increased risk of bleeding, if they are above the targeted range instead of within or below (odds ratio $[\mathrm{OR}]=3.2 ; 95 \%$ confidence interval $[\mathrm{CI}]=1.2-8.3$ ). Inversely, patients with an INR below the targeted therapeutic range have an increased risk of having a thromboembolic event $(\mathrm{OR}=5.1 ; 95 \% \mathrm{CI}=2.9-8.8){ }^{2}$ In order to assess the quality of warfarin anticoagulation control, a linearly interpolated time in therapeutic range (TTR) is commonly used. ${ }^{3}$ A low TTR $(<60 \%)$ is associated with higher rates of major bleeding and thromboembolic events, which indicates the importance of good INR monitoring strategies. ${ }^{4,5}$ Multiple INR monitoring programs do exist, as well as specialized anticoagulation clinics, but patients attending such clinics only have had a mean TTR of $65.4 \% .^{6}$

Multiple studies have shown that adherence to warfarin is a key factor in the achievement of a therapeutic and stable INR. ${ }^{7-12}$ Missing a warfarin dose at least $20 \%$ of the time significantly increases the odds of having a subtherapeutic INR of up to 
2.8 -fold $(P<0.001)$. Inversely, overadherence at least $10 \%$ of the time significantly increases the odds of having a supratherapeutic INR of up to 1.7 -fold $(P=0.02) .{ }^{13}$ Patients can typically be overadherent to warfarin by taking an additional dose 1 day because they forgot that they had already taken their daily dose earlier the same day.

In order to improve adherence, and ultimately clinical outcomes, patients taking warfarin are often encouraged to use a pillbox - a container with compartments that correspond to a day or a period of the day into which the medication can be placed in advance. Pillbox use has already been linked to health improvements among HIV-infected patients taking antiretroviral therapy and patients with uncontrolled hypertension who are taking at least 3 antihypertensive drugs. ${ }^{14,15}$ Therefore, there is an implicit belief that using a pillbox for warfarin improves adherence and ultimately clinical outcomes, but very limited data with a sufficient sample size are actually available to support this belief. ${ }^{16}$ Moreover, studying the link between adherence and pillbox use in a cohort of warfarin users is subject to bias, since pharmacy claims data are unreliable because of the multiple warfarin dose adjustments, and the use of electronic pillboxes (MEMs) would prevent the use of a comparison group. In order to assess the potential benefits from using a pillbox, the purpose of this study is to evaluate the association between pillbox use and 2 clinical outcomes: TTR $<60 \%$ and the INR instability pattern.

\section{Methods}

\section{Patient Selection}

Data were used from the Quebec Warfarin Cohort Study (QWCS), an ongoing prospective and multicentric cohort study that assesses the genetic, clinical, and environmental risk factors associated with the effectiveness and safety of warfarin. The ethics committees of the Montreal Heart Institute (MHI) and the 17 participating hospitals approved the study. All of the participating hospitals had cardiology departments where research nurses could screen patients in order to select potential eligible participants.

Study participants started using warfarin between May 1, 2010, and July 31, 2013. The primary indication for warfarin treatment was atrial fibrillation, mechanical valve replacement, or mitral stenosis. Participants had to be aged at least 18 years in order to participate. Patients excluded from the QWCS were those with a history of clinically important bleedings or a recent gastrointestinal bleeding or hemorrhagic stroke ( $<3$ months before warfarin initiation) and those with known coagulation factors deficiency, chronic thrombocytopenia, hematologic malignancy, cirrhosis, chronic hepatitis, jaundice, or cognitive impairment (unreliability).

\section{Data Collection and Measurements}

Sociodemographic data, comorbidities, previous history of cardiovascular disease, and lifestyle data were collected at baseline by a research nurse approximately 2 weeks after warfarin initiation. Lifestyle data (e.g., alcohol intake, diet, over-the-counter drug use, and natural products use), with the exception of physical activity and smoking, were updated via 4 follow-up telephone interviews that took place 3, 6, 9, and 12 months after initiation of warfarin by research nurses and trained research assistants. Because of the noninterventional nature of this study, patients were asked whether they used a pillbox for warfarin at each of these interviews. If pillboxes were used, patients were asked to clarify whether the pillboxes were self-prepared or prepared by a pharmacist. Those lifestyle and pillbox use data defined patients' habits for the following 3 months to avoid temporality bias. Patients were asked whether they missed any of their warfarin doses or experienced any known deviations in dosage during the previous 3 months to evaluate self-reported adherence. Before the interview, patient-reported warfarin dose regimen for the last 7 days were collected, along with the prescribed warfarin dose regimen corresponding to this period. There was no significant difference between reported and prescribed warfarin dose (Pearson coefficient $=0.969)$, as described in a study using data from the same cohort. ${ }^{17}$

INRs were obtained from each patient's monitoring site. At the 12-month follow-up, $76.2 \%$ of patients were monitored at a hospital-based anticoagulation clinic; $13.9 \%$ were monitored by their physicians; $7.2 \%$ were monitored by a pharmacist; and $1.9 \%$ were monitored with other means, such as selfmonitoring.

\section{CYP2C9 and VKORC1 Genotyping}

Patients provided a blood sample at the beginning of the follow-up for DNA extraction. Genotyping was performed at the Beaulieu-Saucier Pharmacogenomics Centre of the MHI. The Sequenom iPLEX ADME CYP2C9/VKORCl Panel v1.0 (Sequenom, San Diego, CA) was used to genotype samples from QWCS patients. The mass array was analyzed using Sequenom MassArray Typer software (version 4.0.25.73). Genotypes were subjected to data quality check procedures that ensured single nucleotide polymorphism (SNP) and sample completion rates of $98 \%$ or more, absence of platebias effects, absence of sample duplicates, and related individuals based on identical by descent estimates and Hardy-Weinberg equilibrium $(P<0.05)$. Two SNPs from the gene CYP2C9 (rs1799853 or CYP2C9*2; rs1057910 or CYP2C9*3) and 1 SNP from the gene VKORC1 (rs9934438) were used in the this study.

\section{Outcomes Measures}

The TTR was calculated using linear interpolation between available INR measures for each of the follow-up periods (3-6, 6-9, and 9-12 months). ${ }^{18}$ Interview dates were used as delimiters between follow-ups to consider the time-dependant nature of pillbox use. The TTR was also calculated for the entire study period (3-12 months). A TTR was not calculated for the first 3 months of warfarin therapy to discriminate the potential impact of a patient's stabilization period and inexperience with warfarin. A TTR was excluded from the analysis for the corresponding follow-up period if (a) there were more than 70 days (10 weeks) between 2 INR measures and (b) if the patient temporarily 
FIGURE 1 Periods of Data Collection, Study Design, and Losses to Follow-up and Exclusions from the Analyses for Each Follow-up Period

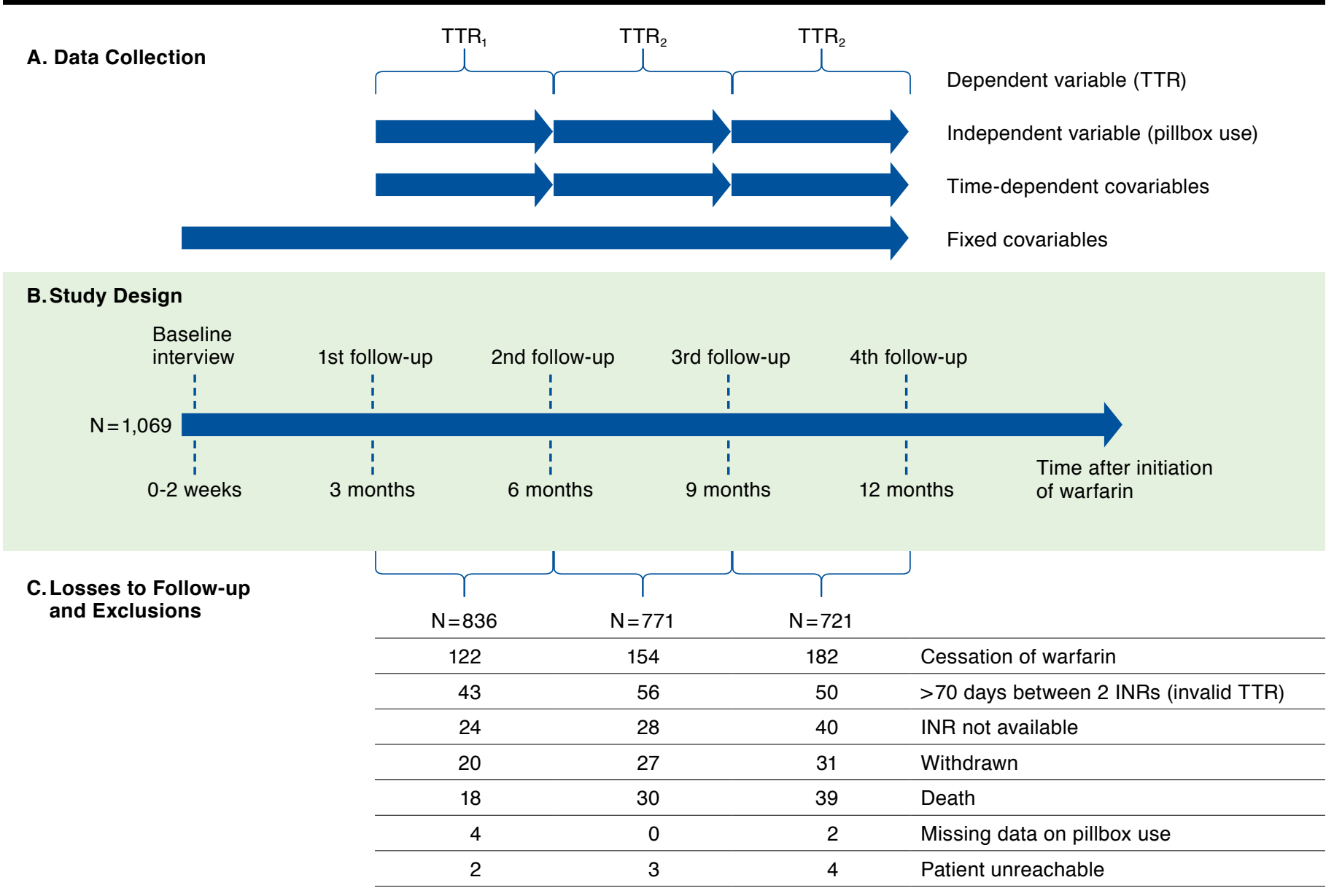

INR = international normalized ratio; TTR = time in therapeutic range.

stopped taking warfarin for more than 7 days. The distribution of the TTR calculated for each segmented follow-up period (3-6, 6-9, and 9-12 months) suggested a lack of normality, which was confirmed by a Shapiro-Wilk (W) test. The TTR calculated for the overall follow-up period (3-12 months) was distributed normally $(\mathrm{W}=0.96)$. We opted to categorize TTRs to obtain an indicator for INR instability (TTR $<60 \%$ ), which represents the primary outcome. This indicator was previously associated with a higher rate of thrombosis and bleeding events. ${ }^{4,5}$

The secondary outcome was the INR instability pattern, which categorizes patients according to the pattern of their outof-range INRs. ${ }^{19}$ Patients with TTR $<60 \%$ and $\geq 75 \%$ of the outof-range time below the therapeutic range were categorized as unstable below range. Patients with TTR $<60 \%$ and $\geq 75 \%$ of the out-of-range time above the therapeutic range were categorized as unstable above range. Patients were categorized as unstable with an erratic pattern when they did not fit the first 2 definitions. Patients with TTR $\geq 60 \%$ were the reference group.

\section{Covariates}

Covariates included age at initiation of warfarin, sex, level of education, and body mass index. The following lifestyle variables were also considered: alcohol intake, green vegetable intake, smoking status, and level of physical activity. Physical activity was evaluated according to the Stanford Brief Activity Survey, a validated questionnaire for cardiac patients. ${ }^{20}$ History of hypertension, diabetes, dyslipidemia, myocardial infarction (MI) or angina, and stroke were also covariates, along with the genotype based on the presence of $\geq 1$ SNP on either the CYP2C9 and VKORC1 gene.

\section{Statistical Analysis}

Users with self-prepared and pharmacist-prepared pillboxes were compared with nonusers for the primary and secondary outcomes between 3 and 12 months of warfarin therapy. The primary outcome $(\mathrm{TTR}<60 \%)$ was tested with a multivariate generalized linear mixed model. As a sensitivity analysis, this outcome was tested using a different threshold (TTR $<45 \%)^{21}$ 

at Each Follow-up Period and Overall

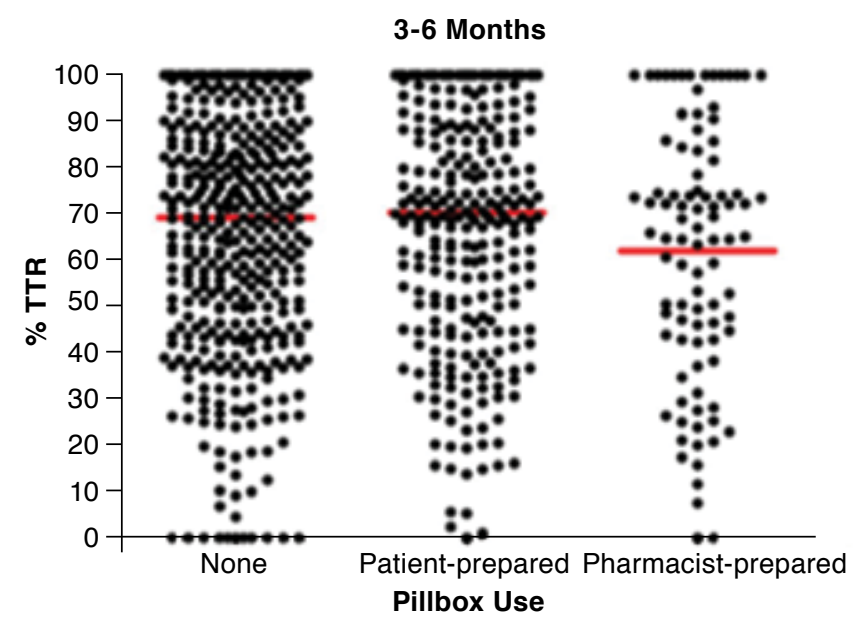

9-12 Months

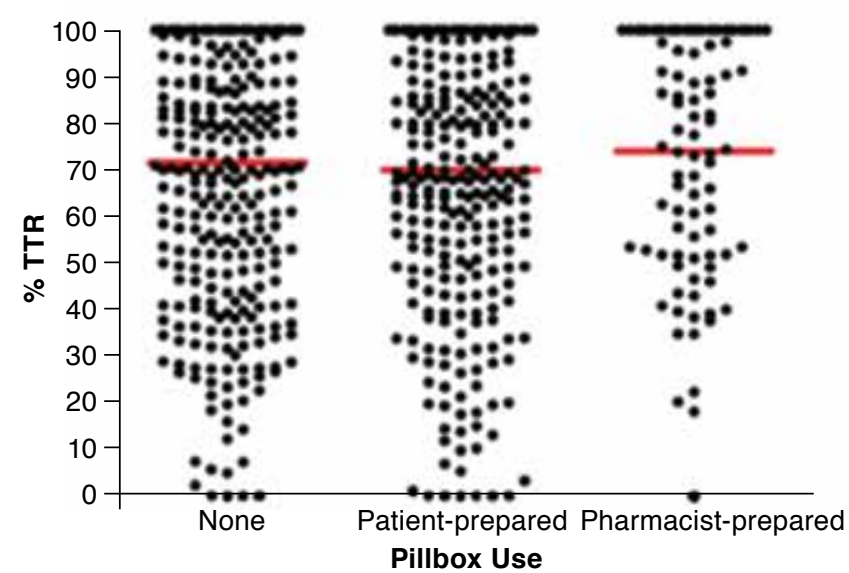

6-9 Months

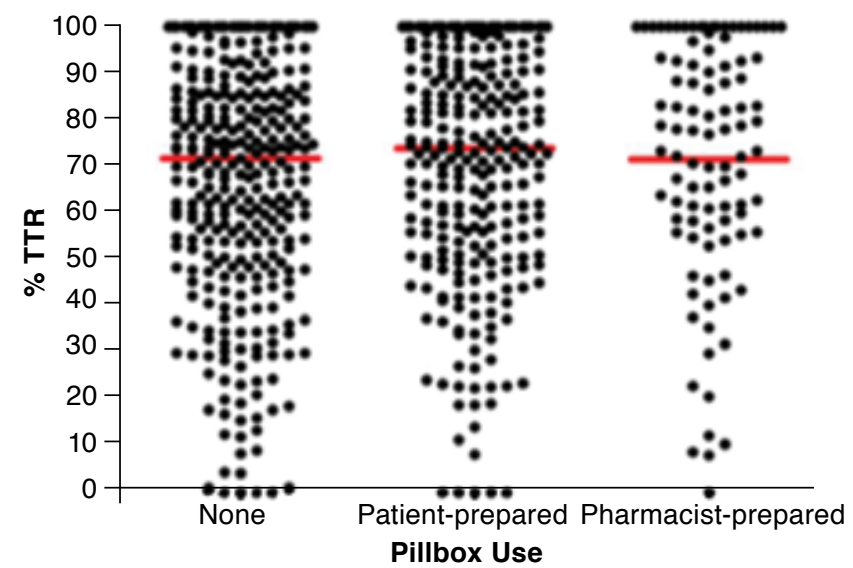

3-12 Months (Overall)

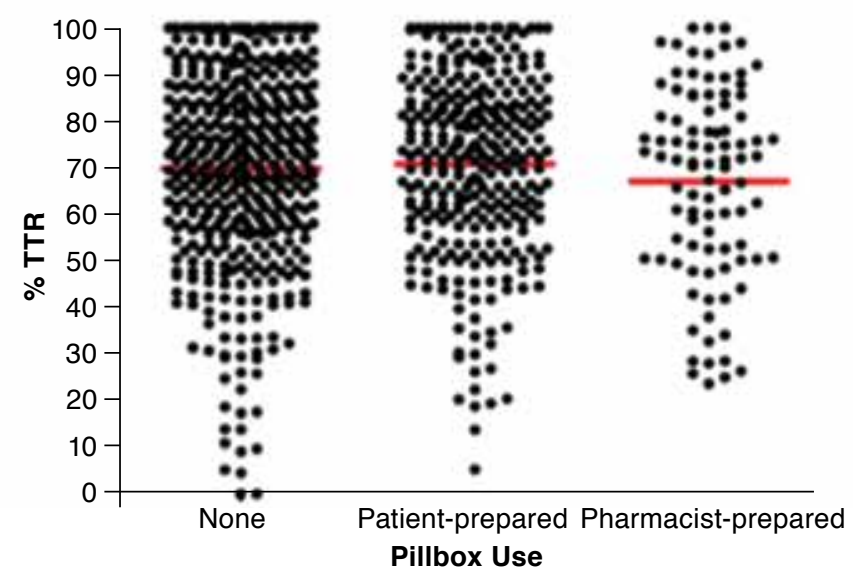

Subgroup average TTR

$T T R=$ time in therapeutic range.

The secondary outcome (INR instability pattern) was tested with a multinomial mixed linear model. Primary and secondary models were implemented with the GLIMMIX procedure in SAS to allow for the time-dependant nature of pillbox use and potential confounders. They could account for up to 3 outcome measures per patient (3-6, 6-9, and 9-12 months of warfarin therapy).

The multivariate models with the lowest Bayesian information criteria were selected. ${ }^{22}$ The final models were adjusted for age, sex, warfarin's indication, history of hypertension, dyslipidemia, diabetes, MI or angina, stroke, green vegetable intake, and genotype. Statistical analyses were conducted with SAS version 9.3 (SAS Institute, Cary, NC).

\section{Sensitivity Analyses}

The overall TTR (3-12 months) was tested as a continuous variable, since it was distributed normally. A multivariate generalized linear regression model was used that was implemented with a GLM procedure in SAS. Since this model cannot account for time-dependent variables, only patients who did not change their habits in terms of pillbox use or nonuse were included ( $\mathrm{n}=817,76.4 \%$ ). Using this model, the potential age-associated differential association between pillbox use and TTR was also explored by stratifying the population based on the cohort mean age at the initiation of warfarin ( $<70$ years; $\geq 70$ years). 
TABLE 1 Patient Characteristics by Type of Pillbox Use 3 Months After the Initiation of Warfarin Therapy

\begin{tabular}{|c|c|c|c|c|c|c|c|c|}
\hline \multirow[b]{2}{*}{ Characteristics } & \multirow{2}{*}{\multicolumn{2}{|c|}{$\begin{array}{c}\text { Nonusers } \\
(\mathrm{N}=519) \\
\mathrm{n}(\%)\end{array}$}} & \multicolumn{3}{|c|}{$\begin{array}{l}\text { Self-Prepared Pillbox Users } \\
\qquad(\mathrm{N}=342)\end{array}$} & \multicolumn{3}{|c|}{$\begin{array}{l}\text { Pharmacist-Prepared Pillbox Users } \\
\qquad(\mathrm{N}=112)\end{array}$} \\
\hline & & & \multicolumn{2}{|c|}{ n (\%) } & $P$ Value ${ }^{a, b}$ & \multicolumn{2}{|c|}{ n (\%) } & $P$ Value $^{\mathrm{b}, \mathrm{c}}$ \\
\hline \multicolumn{9}{|l|}{ Demographic } \\
\hline Age, mean (SD) & 70.4 & $(11.5)$ & 68.5 & (11.9) & 0.022 & 76.9 & (10.9) & $<0.001$ \\
\hline Sex (male) & 335 & $(64.6)$ & 208 & $(60.8)$ & 0.280 & 54 & $(48.2)$ & 0.002 \\
\hline \multicolumn{9}{|l|}{ Education } \\
\hline University or college & 188 & $(36.2)$ & 128 & $(37.4)$ & \multirow{3}{*}{0.116} & 22 & $(19.6)$ & \multirow{3}{*}{$<0.001$} \\
\hline High school & 142 & (27.4) & 111 & $(32.5)$ & & 14 & $(12.5)$ & \\
\hline No degree & 189 & (36.4) & 103 & $(30.1)$ & & 76 & $(67.9)$ & \\
\hline Body mass index $\geq 30$ & 171 & $(33.0)$ & 119 & $(34.8)$ & 0.606 & 39 & (34.8) & 0.740 \\
\hline \multicolumn{9}{|l|}{ Lifestyle } \\
\hline \multicolumn{9}{|l|}{ Alcohol intake } \\
\hline Nondrinker & 168 & $(32.4)$ & 111 & $(32.5)$ & \multirow{4}{*}{0.846} & 55 & $(49.1)$ & \multirow{4}{*}{0.006} \\
\hline Occasional drinker & 175 & $(33.7)$ & 122 & $(35.7)$ & & 33 & $(29.5)$ & \\
\hline Regular drinkerd & 132 & $(25.4)$ & 85 & $(24.9)$ & & 18 & $(16.1)$ & \\
\hline Heavy drinkere & 44 & $(8.5)$ & 24 & $(7.0)$ & & 6 & (5.4) & \\
\hline Regular intake of green vegetables ${ }^{f}$ & 221 & $(42.7)$ & 163 & $(47.8)$ & 0.142 & 33 & $(30.0)$ & 0.014 \\
\hline \multicolumn{9}{|l|}{ Smoking status } \\
\hline Never smoker & 159 & $(30.6)$ & 119 & $(34.8)$ & \multirow{3}{*}{0.322} & 36 & $(32.4)$ & \multirow{3}{*}{0.793} \\
\hline Former smoker $>5$ years & 252 & $(48.6)$ & 163 & $(47.7)$ & & 55 & $(49.6)$ & \\
\hline Former smoker $\leq 5$ years or current smoker & 108 & $(20.8)$ & 60 & $(17.5)$ & & 20 & $(18.0)$ & \\
\hline Moderate, high, or very high level of physical activityg & 144 & $(27.8)$ & 91 & $(26.6)$ & 0.755 & 16 & $(14.3)$ & 0.003 \\
\hline \multicolumn{9}{|l|}{ Indication for warfarin treatment } \\
\hline Atrial fibrillation & 390 & $(75.1)$ & 246 & $(71.9)$ & 0.304 & 89 & $(76.5)$ & 0.394 \\
\hline Mechanic valve replacement & 80 & $(15.4)$ & 58 & $(17.0)$ & 0.570 & 7 & $(6.3)$ & 0.010 \\
\hline Flutter & 53 & $(10.2)$ & 38 & $(11.1)$ & 0.734 & 14 & $(12.5)$ & 0.499 \\
\hline Stenonis & 5 & $(1.0)$ & 6 & $(1.8)$ & 0.360 & 1 & $(0.9)$ & 1.000 \\
\hline Other & 3 & $(0.6)$ & 3 & $(0.9)$ & 0.687 & 2 & (1.8) & 0.217 \\
\hline \multicolumn{9}{|l|}{ INR therapeutic range } \\
\hline $2.0-3.0$ & 452 & $(87.1)$ & 295 & $(86.3)$ & \multirow{2}{*}{0.758} & 107 & $(95.5)$ & \multirow{2}{*}{0.008} \\
\hline $2.5-3.5$ & 67 & $(12.9)$ & 47 & $(13.7)$ & & 5 & $(4.5)$ & \\
\hline \multicolumn{9}{|l|}{ Clinical comorbidity } \\
\hline Hypertension & 360 & $(69.9)$ & 220 & $(64.7)$ & 0.117 & 86 & $(76.8)$ & 0.168 \\
\hline Diabetes & 127 & $(24.5)$ & 92 & $(27.0)$ & 0.425 & 47 & $(42.0)$ & $<0.001$ \\
\hline Dyslipidemia & 309 & $(60.1)$ & 216 & $(63.7)$ & 0.314 & 71 & $(64.6)$ & 0.451 \\
\hline \multicolumn{9}{|l|}{ Prior history of cardiovascular disease } \\
\hline History of myocardial infraction or angina & 176 & $(34.5)$ & 121 & $(36.5)$ & 0.606 & 56 & $(51.4)$ & 0.002 \\
\hline History of stroke & 39 & $(7.6)$ & 23 & $(6.8)$ & 0.688 & 9 & $(8.1)$ & 0.845 \\
\hline Genotype & & & & & & & & \\
\hline No SNP on CYP2C9/No SNP on VKORCl & 118 & $(22.7)$ & 90 & $(26.3)$ & & 24 & $(21.4)$ & \\
\hline No SNP on CYP2C9/ $\geq 1$ SNP on VKORCl & 212 & $(40.8)$ & 118 & $(34.5)$ & 0256 & 43 & $(38.4)$ & 324 \\
\hline$\geq 1$ SNP on CYP2C9/No SNP on VKORCl & 66 & $(12.7)$ & 45 & $(13.2)$ & 0.256 & 21 & $(18.8)$ & 0.384 \\
\hline$\geq 1$ SNP on CYP2C9/ 1 SNP on VKORCl & 118 & $(22.7)$ & 88 & $(25.7)$ & & 22 & $(19.6)$ & \\
\hline $\begin{array}{l}\text { a Self-prepared pillbox users compared with nonusers. } \\
b T \text { test for continuous variables and Fisher's exact test for bina } \\
\text { cPharmacist-prepared pillbox users compared with nonusers. } \\
d_{<15} \text { drinks per week for men and }<8 \text { drinks per week for won } \\
e_{\geq 15} \text { drinks per week for men and } \geq 8 \text { drinks per week for won } \\
f_{\geq 4} \text { times per week. } \\
\text { gSBAS score } \geq 3 \text {. } \\
\text { INR }=\text { international normalized ratio; SBAS = Stanford Brief Ac }\end{array}$ & 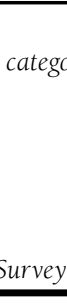 & cal var & & & & & & \\
\hline
\end{tabular}


TABLE 2 Multivariate Generalized Linear Mixed Model on Association Between Pillbox Use and TTR $<60 \%$ Between 3 and 12 Months of Warfarin Therapy (All Patients, $N=1,069$ )

\begin{tabular}{|c|c|c|c|c|c|c|c|c|c|}
\hline \multirow[b]{2}{*}{ Independent Variable } & \multicolumn{2}{|c|}{ 3-6 Months } & \multicolumn{2}{|c|}{ 6-9 Months } & \multicolumn{2}{|c|}{ 9-12 Months } & \multirow[b]{2}{*}{$\begin{array}{l}\text { Adjusted } \\
\text { OR }^{\mathrm{a}}\end{array}$} & \multirow[b]{2}{*}{$95 \%$ CI } & \multirow[b]{2}{*}{$\begin{array}{c}P \\
\text { Value }\end{array}$} \\
\hline & n (\%) & $\begin{array}{c}\text { TTR }<60 \% \\
\text { n }(\%)\end{array}$ & n (\%) & $\begin{array}{c}\text { TTR }<60 \% \\
\text { n }(\%)\end{array}$ & n (\%) & $\begin{array}{c}\text { TTR }<60 \% \\
\text { n }(\%)\end{array}$ & & & \\
\hline Self-prepared pillbox & $342(32.0)$ & $104(30.4)$ & $358(33.5)$ & $92(25.7)$ & $354(33.1)$ & $97(27.4)$ & 0.86 & $0.70-1.05$ & 0.129 \\
\hline Pharmacist-prepared pillbox & $112(10.5)$ & $41(36.6)$ & $116(10.9)$ & $28(24.1)$ & $111(10.4)$ & $31(27.9)$ & 1.15 & $0.85-1.56$ & 0.357 \\
\hline No pillbox & $519(48.6)$ & $158(30.4)$ & $431(40.3)$ & $118(27.4)$ & $382(35.7)$ & $109(28.5)$ & & reference & \\
\hline
\end{tabular}

aAdjusted with pillbox use, age, sex, warfarin's indication, hypertension, dyslipidemia, diabetes, myocardial infarction or angina history, stroke history, green vegetable intake, and genotype.

$C I=$ confidence interval; $O R=$ odds ratio; $T T R=$ time in therapeutic range.

\section{Results}

\section{Demographic and Clinical Data}

As of July 31, 2013, 1,069 participants were enrolled in the QWCS to complete a 1-year follow-up. Of those participants, 836,771 , and 721 were included in the analyses for the followup periods at 3-6, 6-9, and 9-12 months, respectively (Figure 1). The major reason for sample size reduction was related to warfarin cessation. At each of the follow-up periods, approximately $43 \%$ of patients were using a pillbox that included warfarin, of which about $75 \%$ self-prepared their pillboxes. An increase of the mean TTR was observed across the follow-up periods, as well as a high variability among all subgroups of patients (Figure 2).

As shown in Table 1, the demographic and clinical characteristics are quite similar between nonusers and self-prepared pillbox users (except for age). On the other hand, pharmacistprepared pillbox users were older, disproportionally female, less educated, differed in their alcohol and green vegetable intake, were less active, more diabetic, had a greater history of MI or angina, and were less prone to have a mechanic valve replacement as a main indication for warfarin than nonusers.

\section{Instability Indicator (TTR $<60 \%)$}

Self-prepared pillbox use showed a nonsignificant trend towards a lower risk of TTR $<60 \%(\mathrm{OR}=0.86 ; 95 \% \mathrm{CI}=0.70-1.05$; $P=0.129$ ). Pharmacist-prepared pillbox use was not associated with a TTR $<60 \%(\mathrm{OR}=1.15 ; 95 \% \mathrm{CI}=0.85-1.56 ; \mathrm{P}=0.357$; Table 2). Age was protective against TTR $<60 \%(\mathrm{OR}=0.98 ; 95 \%$ $\mathrm{CI}=0.97-0.98 ; \mathrm{P}=0.001)$. History of hypertension $(\mathrm{OR}=1.33$; $95 \% \mathrm{CI}=1.07-1.66 ; P=0.012)$ and history of $\mathrm{MI}$ or angina $(\mathrm{OR}=1.24 ; 95 \% \mathrm{CI}=1.00-1.53 ; \mathrm{P}=0.047)$ were risk factors for TTR $<60 \%$.

When changing the threshold to define INR instability to TTR $<45 \%$ and using the same confounders, results were similar. Patient-prepared pillbox users $(\mathrm{OR}=0.81 ; 95 \%$ $\mathrm{CI}=0.64-1.03 ; \quad P=0.087)$ and pharmacist-prepared pillbox users $(\mathrm{OR}=1.04 ; 95 \% \mathrm{CI}=0.72-1.50 ; \mathrm{P}=0.851)$ were still comparable with nonusers (data not shown).

\section{INR Instability Patterns}

The majority of unstable patients were below range between 3 and 6 months of warfarin therapy, but this proportion decreased until the end of the follow-up period (58.1\%-41.0\%). On the other hand, there was a growing proportion of patients who were unstable above therapeutic range or with an erratic pattern (24.4\%-35.8\% and 17.8\%-23.2\%, respectively).

Self-prepared pillbox users tended to be less at risk of being unstable above range $(\mathrm{OR}=0.78 ; 95 \% \mathrm{CI}=0.57-1.07 ; \mathrm{P}=0.123)$ and below range $(\mathrm{OR}=0.84 ; 95 \% \mathrm{CI}=0.65-1.08 ; \mathrm{P}=0.174)$ when compared with nonusers, but results were not significant (Table 3).

\section{Sensitivity Analyses}

Using the overall TTR as a continuous variable, self-prepared pillbox users had a significantly higher adjusted TTR than nonusers ( $3.55 \pm 1.69 ; P=0.036$; Table 4). Using the same model, but subgrouping for age, the impact of self-prepared pillbox use seemed greater among patients aged $<70$ years $(5.48 \pm 2.50$; $P=0.029)$ than older patients $(1.92 \pm 2.31 ; P=0.406)$. Finally, women had a significantly lower TTR than men $(3.70 \pm 1.67$; $P=0.027$ ), and patients with an INR target between 2.5 and 3.5 had a lower TTR than patients with an INR target between 2.0 and $3.0(-7.35 \pm 2.62 ; P=0.005)$.

\section{Discussion}

The impact of pillbox use on INR instability among new users of warfarin was assessed by testing the association of pillbox use with a TTR $<60 \%$ indicator and the INR instability pattern. Results were not significant with regards to the primary and secondary outcomes. In the sensitivity analysis, patients using a self-prepared pillbox had a significantly, but not clinically, higher TTR than nonusers. Patients aged $<70$ years seemed to derive more benefit from self-prepared pillbox use than older patients.

According to this study's results, patients aged $\geq 70$ years had a more stable INR profile during the follow-up period than younger patients. Previous studies have reported an association between younger age and warfarin nonadherence and INR instability. ${ }^{11,23,24}$ This association could support this 
TABLE 3 Multivariate Model of INR Instability Pattern Between 3 and 12 Months of Warfarin Therapy $(N=1,069)^{a}$

\begin{tabular}{|c|c|c|c|c|c|c|c|c|c|c|}
\hline \multirow{2}{*}{$\begin{array}{l}\text { Independent } \\
\text { Variable }\end{array}$} & \multirow{2}{*}{$\begin{array}{l}\text { INR Instability } \\
\text { Pattern }\end{array}$} & \multicolumn{2}{|c|}{ 3-6 Months } & \multicolumn{2}{|c|}{ 6-9 Months } & \multicolumn{2}{|c|}{ 9-12 Months } & \multirow{2}{*}{$\begin{array}{l}\text { Adjusted } \\
\mathrm{OR}^{\mathrm{e}}\end{array}$} & \multirow[b]{2}{*}{$95 \%$ CI } & \multirow[b]{2}{*}{$P$ Value } \\
\hline & & $\mathrm{N}$ & n (\%) & $\mathrm{N}$ & n (\%) & $\mathrm{N}$ & n (\%) & & & \\
\hline \multirow{4}{*}{$\begin{array}{l}\text { Self-prepared } \\
\text { pillbox }\end{array}$} & Stable $(\mathrm{TTR} \geq 60 \%)$ & \multirow{4}{*}{342} & $205(59.9)$ & \multirow{4}{*}{358} & $212(59.2)$ & \multirow{4}{*}{354} & $203(57.3)$ & \multicolumn{3}{|c|}{ reference } \\
\hline & Unstable below range ${ }^{b}$ & & $57(16.7)$ & & $45(12.6)$ & & $36(10.2)$ & 0.84 & $0.65-1.08$ & 0.174 \\
\hline & Unstable above range $^{c}$ & & $23 \quad(6.7)$ & & $30 \quad(8.4)$ & & $36(10.2)$ & 0.78 & $0.57-1.07$ & 0.123 \\
\hline & Erratic pattern $^{\mathrm{d}}$ & & $14 \quad(4.1)$ & & $12 \quad(3.4)$ & & $25 \quad(7.1)$ & 0.99 & $0.66-1.49$ & 0.975 \\
\hline \multirow{4}{*}{$\begin{array}{l}\text { Pharmacist- } \\
\text { prepared } \\
\text { pillbox }\end{array}$} & Stable $(\mathrm{TTR} \geq 60 \%)$ & \multirow{4}{*}{112} & $42(48.2)$ & \multirow{4}{*}{116} & $70(60.3)$ & \multirow{4}{*}{111} & $63(56.8)$ & \multicolumn{3}{|c|}{ reference } \\
\hline & Unstable below range ${ }^{b}$ & & $34(20.5)$ & & $13(11.2)$ & & $13(11.7)$ & 1.27 & $0.87-1.86$ & 0.219 \\
\hline & Unstable above range ${ }^{c}$ & & $10 \quad(8.9)$ & & $9 \quad(7.8)$ & & $10 \quad(9.0)$ & 0.95 & $0.59-1.53$ & 0.837 \\
\hline & Erratic pattern ${ }^{\mathrm{d}}$ & & $7 \quad(6.3)$ & & $6 \quad(5.2)$ & & $6 \quad(5.4)$ & 1.29 & $0.72-2.30$ & 0.395 \\
\hline \multirow[t]{4}{*}{ No pillbox } & Stable $(\mathrm{TTR} \geq 60 \%)$ & \multirow{4}{*}{519} & $291 \quad(56.1)$ & \multirow{4}{*}{431} & $258(59.9)$ & \multirow{4}{*}{382} & $222(58.1)$ & \multicolumn{3}{|c|}{ reference } \\
\hline & Unstable below range ${ }^{b}$ & & $84(16.2)$ & & $48(11.1)$ & & $47(12.3)$ & \multicolumn{3}{|c|}{ reference } \\
\hline & Unstable above range ${ }^{c}$ & & $36 \quad(6.9)$ & & 49 (11.4) & & $50(13.1)$ & \multicolumn{3}{|c|}{ reference } \\
\hline & Erratic pattern ${ }^{\mathrm{d}}$ & & $32 \quad(6.2)$ & & $19 \quad(4.4)$ & & $10 \quad(2.6)$ & \multicolumn{3}{|c|}{ reference } \\
\hline
\end{tabular}

a Multivariate multinomial generalized linear mixed model.

${ }^{b} \mathrm{TTR}<60 \%$ and $\geq 75 \%$ of time out of range below therapeutic range.

CTTR $<60 \%$ and $\geq 75 \%$ of time out of range above therapeutic range.

$d T T R<60 \%$ and no specific pattern below or above range.

eAdjusted with age, hypertension, myocardial infarction or angina history, and genotype.

$C I=$ confidence interval; INR = international normalized ratio; $O R=$ odds ratio; $T T R=$ time in therapeutic range

study's finding of a greater impact from self-prepared pillbox use among young patients taking warfarin. MI or angina history was associated with an increased INR instability, which could be an indicator of decreased adherence because of its link with depression and anxiety or co-medication use. ${ }^{25-27}$ Previous work conducted with the QWCS found that MI history was associated with a lower concordance between self-reported and prescribed warfarin doses. ${ }^{17}$ Hypertension was associated with an increased odds of having TTR $<60 \%$ but not with a lower TTR. History of MI or angina and hypertension could be indicators of an increased number of concomitant drugs and thus an increased risk of drug interactions with warfarin. Previous studies reported that various comorbidities were linked to a lower TTR and lower adherence, which reinforced this hypothesis. ${ }^{28-30}$ Finally, female sex and an INR target range of 2.5-3.5 were risk factors for a low TTR, which is concordant with results from previous studies. ${ }^{24,29}$

This study is the first prospective cohort study that reports the impact of pillbox use on INR instability among warfarin users. It is also the first study to evaluate the impact of selfprepared pillbox use on this outcome in a real clinical setting. Results are generalizable to other populations of new warfarin users who have access to an anticoagulation monitoring program. A previous study did show an improved TTR from the use of clinician-prepared pillboxes, but the sample size was small $(n=13)$. Moreover, the data were compared with preenrollment data, which suggests that the results might actually reflect a change in patients' behaviors in this 3-month study (i.e., Hawthorne effect). ${ }^{14}$ An observational study, such as the present study, is indeed an adequate study setting for these research objectives, since a randomized controlled trial may raise ethical concerns. Pillbox use is recommended by guidelines on warfarin management and is already part of the dayto-day life of $53.1 \%$ of patients taking warfarin. ${ }^{31-33}$

A particular strength of this study is the ability to discriminate between self-prepared and pharmacist-prepared pillbox users. In addition, the use of an incident-user cohort has allowed consideration of the time-dependent nature of pillbox use and other covariables in a mixed regression model. Also, the use of the INR instability pattern as a secondary outcome allows for greater precision in the evaluation of the impact of interventions among warfarin users.

\section{Limitations}

Some of the limitations of this study should be mentioned. In particular, it was not possible to directly measure the impact of pillbox use on adherence. Pharmacy claims data can be unreliable because of the multiple warfarin dose adjustments, and the use of electronic pillboxes (MEMs) would create a bias in this particular study. However, no significant difference was found between reported and prescribed warfarin dose (Pearson coefficient $=0.969$ ), suggesting a good compliance from the QWCS participants to prescriber recommendations. ${ }^{15}$ Indeed, it was possible to test for self-reported adherence at each interview, with some reservation, since this variable could be biased. When asked, pillbox users tend to recall missed doses better than nonusers, since the latter do not have any visual clue of their omissions and are therefore more quick to perceive themselves as perfectly adherent. This recall bias could result in falsely considering pillbox use as a risk factor for 
TABLE 4 Multivariate Generalized Linear Regression Model on Association Between Pillbox Use and TTR Between 3 and 12 Months of Warfarin Therapy $(N=817)^{a}$

\begin{tabular}{|c|c|c|c|c|c|c|c|}
\hline Independent Variable & Age Subgroup & $\mathbf{n}$ & Mean & [R (SD) & $\begin{array}{c}\text { Adjusted } \\
\text { Coefficient }^{\mathrm{b}}\end{array}$ & SE & $P$ Value \\
\hline \multirow[t]{3}{*}{ Self-prepared pillbox } & $<70$ years & 159 & 69.3 & $(31.0)$ & 5.48 & 2.50 & 0.029 \\
\hline & $\geq 70$ years & 145 & 73.4 & $(27.0)$ & 1.92 & 2.31 & 0.406 \\
\hline & All patients & 304 & 71.3 & $(29.4)$ & 3.55 & 1.69 & 0.036 \\
\hline \multirow{3}{*}{$\begin{array}{l}\text { Pharmacist-prepared } \\
\text { pillbox }\end{array}$} & $<70$ years & 18 & 62.3 & $(25.9)$ & -3.21 & 5.67 & 0.572 \\
\hline & $\geq 70$ years & 79 & 69.4 & $(28.6)$ & -1.89 & 2.93 & 0.520 \\
\hline & All patients & 97 & 68.0 & $(28.0)$ & -2.75 & 2.57 & 0.285 \\
\hline \multirow[t]{3}{*}{ No pillbox } & $<70$ years & 161 & 66.6 & (21.8) & \multicolumn{3}{|c|}{ reference } \\
\hline & $\geq 70$ years & 251 & 71.8 & $(21.1)$ & \multicolumn{3}{|c|}{ reference } \\
\hline & All patients & 412 & 69.8 & $(32.1)$ & \multicolumn{3}{|c|}{ reference } \\
\hline
\end{tabular}

axcluding patients whose pillbox use changed during follow-up $(n=817)$ and excluding time-dependent predictors.

${ }^{b}$ Adjusted with pillbox use, sex, INR target range, hypertension, myocardial infarction or angina history, level of education, and genotype.

$I N R=$ international normalized ratio; $S D=$ standard deviation; $S E=$ standard error; TTR=time in therapeutic range.

nonadherence. Using an age-adjusted logistic regression, it was demonstrated that there was indeed a tendency to a higher risk of reporting nonadherence among self-prepared pillbox users when compared with nonusers (OR $=1.22 ; 95 \% \mathrm{CI}=0.90-1.65)$. Similar but significant results were also seen among pharmacist-prepared pillbox users (OR $=2.36 ; 95 \% \mathrm{CI}=1.55-3.59)$.

The absence of concomitant drug information could explain the inability to detect an association with primary and secondary outcomes. Pillbox users could use a greater number of medications than nonusers and be more subject to drug interactions and an increase in INR instability. Therefore, it is possible that true association was overestimated in these analyses. In addition, data on pillbox use was only collected every 3 months during the first year of warfarin therapy, so the exact date of any change in pillbox use or nonuse was not captured. To prevent any temporality bias, the pillbox use data reported at the interview before the follow-up period analysed was considered, not the interview following. Moreover, $76.4 \%$ of patients did not change their pillbox use habits during the follow-up, which minimized the issue.

Another limitation of this study was the growing number of losses to follow-up and exclusions from analysis by the time of the 12-month follow-up interview. The main cause was the discontinuation or temporary cessation of warfarin, which was an inevitable event in this observational study. Finally, a healthy user bias may have been present in this study. Pillbox users could have had generally healthier behaviors than nonusers.

\section{Conclusions}

This study suggests that pillbox use was not associated with TTR $<60 \%$ or INR instability, but these results may be biased by unmeasured confounders such as concomitant drug use. Selfprepared pillbox users had a slightly higher TTR than nonusers, which was more apparent in younger patients. Although further research is still needed in this area, the promotion of pillbox use among warfarin users may help achieve therapeutic goals more quickly and safely, which would reduce the need for frequent monitoring visits.

\section{Authors}

STÉPHANIE DUMAS, BSc, Faculty of Pharmacy, Université de Montréal, and Montreal Heart Institute, Beaulieu-Saucier Université de Montréal Pharmacogenomics Centre, Montreal, Quebec, Canada. ETIENNE ROULEAU-MAILLOUX, MSc, Montreal Heart Institute, Beaulieu-Saucier Université de Montréal Pharmacogenomics Centre, and Faculty of Medicine, Department of Pharmacology, Université de Montréal, Quebec, Canada. NAWAL BOUCHAMA, BSc; HALEMA LAHCENE, BSc; and SYLVIE PERREAULT, BPharm, PhD, Faculty of Pharmacy, Université de Montréal, Quebec, Canada. MARIO TALAJIC, MD, FRCPC, FACC, Montreal Heart Institute, Beaulieu-Saucier Université de Montréal Pharmacogenomics Centre, and Faculty of Medicine, Department of Medicine, Université de Montréal; JEAN-CLAUDE TARDIF, MD, FRCPC, FACC, FCAHS, Montreal Heart Institute, Beaulieu-Saucier Université de Montréal Pharmacogenomics Centre, and Faculty of Medicine, Department of Medicine, Université de Montréal; and MARIE-PIERRE DUBÉ, PhD, Montreal Heart Institute, Beaulieu-Saucier Université de Montréal Pharmacogenomics Centre, and Faculty of Medicine, Department of Medicine, Université de Montréal, Quebec, Canada. MARIEJOSÉ GAULIN, BSc, and SYLVIE PROVOST, MSc, Montreal Heart Institute, Beaulieu-Saucier Université de Montréal Pharmacogenomics Centre, Montreal, Quebec, Canada.

AUTHOR CORRESPONDENCE: Sylvie Perreault, BPharm, PhD, Chaire Sanofi Canada Endowment Chair in Drug Utilization, Faculty of Pharmacy, Université de Montréal, C.P. 6128, succ. Centre-ville, Montréal 2C H3C 3J7 CANADA. E-mail: sylvie.perreault@umontreal.ca. 


\section{DISCLOSURES}

This study was funded by Canadian Institutes of Health Research (CIHR) and the Centre for Excellence in Personalised Medicine. Both funding sources were not involved in the design, conduct, and reporting of this study. The data used for this study came from the Quebec Warfarin Cohort Study (QWCS), which was supported by the CIHR and the Centre for Excellence in Personalised Medicine. Dumas received a doctoral training award from the CIHR. Perreault and Dubé received a salary award from the Fonds Québécois de Recherche en Santé.

Study concept and design were contributed by Talajic, Tardif, Dubé, and Perreault. Dumas, Rouleau-Mailloux, Bouchama, and Lahcene collected the data, which was interpreted by Dumas, Dubé, and Perreault. The manuscript was written and revised by Dumas, Dubé, and Perreault.

\section{ACKNOWLEDGMENTS}

The authors thank all participants, nurses, and research assistants involved in this study.

\section{REFERENCES}

1. IMS Health. Top 25 medicines by dispensed prescriptions (U.S.). May 2013. Available at: https://www.imshealth.com/files/web/Corporate/ News/Top-Line\%20Market\%20Data/US_Top_25_Medicines_Dispensed_ Prescriptions.pdf. Accessed April 22, 2016.

2. Reynolds MW, Fahrbach K, Hauch O, et al. Warfarin anticoagulation and outcomes in patients with atrial fibrillation: a systematic review and metaanalysis. Chest. 2004;126(6):1938-45

3. Schmitt L, Speckman J, Ansell J. Quality assessment of anticoagulation dose management: comparative evaluation of measures of time-in-therapeutic range. J Thromb Thrombolysis. 2003;15(3):213-16.

4. White HD, Gruber M, Feyzi J, et al. Comparison of outcomes among patients randomized to warfarin therapy according to anticoagulant control: results from SPORTIF III and V. Arch Intern Med. 2007;167(3):239-45.

5. Rose AJ, Ozonoff A, Henault LE, Hylek EM. Warfarin for atrial fibrillation in community-based practise. J Thromb Haemost. 2008;6(10):1647-54.

6. van Walraven C, Jennings A, Oake N, Fergusson D, Forster AJ. Effect of study setting on anticoagulation control: a systematic review and metaregression. Chest. 2006;129(5):1155-66

7. Palareti G, Legnani C, Guazzaloca G, et al. Risks factors for highly unstable response to oral anticoagulation: a case-control study. Br J Haematol. 2005;129(1):72-78

8. Laporte S, Quenet S, Buchmüller-Cordier A, et al. Compliance and stability of INR of two oral anticoagulants with different half-lives: a randomised trial. Thromb Haemost. 2003;89(3):458-67.

9. Cavallari LH, Aston JL, Momary KM, Shapiro NL, Patel SR, Nutescu EA. Predictors of unstable anticoagulation in African Americans. J Thromb Thrombolysis. 2009;27(4):430-37.

10. Hixson-Wallace JA, Dotson JB, Blakey SA. Effect of regimen complexity on patient satisfaction and compliance with warfarin therapy. Clin Appl Thromb Hemost. 2001;7(1):33-37.

11. Waterman AD, Milligan PE, Bayer L, Banet GA, Gatchel SK, Gage BF Effect of warfarin nonadherence on control of the International Normalized Ratio. Am J Health Syst Pharm. 2004;61(12):1258-64.

12. Jorgensen AL, Hughes DA, Hanson A, et al. Adherence and variability in warfarin dose requirements: assessment in a prospective cohort. Pharmacogenomics. 2013;14(2):151-63.

13. Kimmel SE, Chen Z, Price M, et al. The influence of patient adherence on anticoagulation control with warfarin: results from the International Normalized Ratio Adherence and Genetics (IN-RANGE) Study. Arch Intern Med. 2007;167(3):229-35.

14. Petersen ML, Wang Y, van der Laan MJ, Guzman D, Riley E, Bangsberg DR. Pillbox organizers are associated with improved adherence to HIV antiretroviral therapy and viral suppression: a marginal structural model analysis. Clin Infect Dis. 2007;45(7):908-15.
15. Porter AK, Taylor SR, Yabut AH, Al-Achi A. Impact of a pill box clinic to improve systolic blood pressure in veterans with uncontrolled hypertension taking 3 or more antihypertensive medications. J Manag Care Spec Pharm. 2014;20(9):905-11. Available at: http://www.jmcp.org/doi/abs/10.18553/ jmcp.2014.20.9.905

16. Nochowitz B, Shapiro NL, Nutescu EA, Cavallari LH. Effect of a warfarin adherence aid on anticoagulation control in an inner-city anticoagulation clinic population. Ann Pharmacother. 2009;43(7):1165-72.

17. Dumas S, Rouleau-Mailloux E, Barhdadi A, et al. Validation of patient-reported warfarin dose in a prospective incident cohort study. Pharmacoepidemiol Drug Saf. 2014;23(3):285-89.

18. Rosendaal FR, Cannegieter SC, van der Meer FJ, Briët E. A method to determine the optimal intensity of oral anticoagulant therapy. Thromb Haemost. 1993;69(3):236-39.

19. Razouki Z, Ozonoff A, Zhao S, Rose AJ. Pathways to poor anticoagulation control. J Thromb Haemost. 2014;12(5):628-34.

20. Taylor-Piliae RE, Fair JM, Haskell WL, et al. Validation of the Stanford Brief Activity Survey: examining psychological factors and physical activity levels in older adults. J Phys Act Health. 2010;7(1):87-94.

21. Veeger NJ, Piersma-Wichers M, Tijssen JG, Hillege HL, van der Meer J. Individual time within target range in patients treated with vitamin $\mathrm{K}$ antagonists: main determinant of quality of anticoagulation and predictor of clinical outcome. A retrospective study of 2300 consecutive patients with venous thromboembolism. Br J Haematol. 2005;128(4):513-19.

22. Kass RE, Raftery AE. Bayes factors. J Am Stat Assoc. 1995;90(430):773-95. 23. Arnsten JH, Gelfand JM, Singer DE. Determinants of compliance with anticoagulation: a case-control study. Am J Med. 1997;103(1):11-17.

24. Witt DM, Delate T, Clark NP, et al. Outcomes and predictors of very stable INR control during chronic anticoagulation therapy. Blood. 2009;114(5):952-56.

25. Kuhl EA, Fauerbach JA, Bush DE, Ziegelstein RC. Relation of anxiety and adherence to risk-reducing recommendations following myocardial infarction. Am J Cardiol. 2009;103(12):1629-34.

26. Rieckmann N, Kronish IM, Haas D, et al. Persistent depressive symptoms lower aspirin adherence after acute coronary syndromes. Am Heart J. 2006;152(5):922-27.

27. Carney RM, Freedland KE, Eisen SA, Rich MW, Jaffe AS. Major depression and medication adherence in elderly patients with coronary artery disease. Health Psychol. 1995;14(1):88-90.

28. Nelson WW, Choi JC, Vanderpoel J, et al. Impact of co-morbidities and patient characteristics on international normalized ratio control over time in patients with nonvalvular atrial fibrillation. Am J Cardiol. 2013;112(4):509-12. 29. Piccini JP, Hellkamp AS, Lokhnygina Y, et al. Relationship between time in therapeutic range and comparative treatment effect of rivaroxaban and warfarin: results from the ROCKET AF trial. J Am Heart Assoc. 2014;3(2):e000521

30. Knafl GJ, Riegel B. What puts heart failure patients at risk for poor medication adherence? Patient Prefer Adherence. 2014:8:1007-18.

31. Medical Services Commission. Warfarin therapy management. October 1, 2010. Victoria, British Columbia. Available at: https://www.guidelinecentral.com/summaries/warfarin-therapy-management/\#h2_scope. Accessed April 22, 2016.

32. Thrombosis Canada. Warfarin: management of out-of-range INRs. October 10, 2015. Available at: http://thrombosiscanada.ca/wp-content/ uploads/2015/11/15_Warfarin-Out-of-Range-INR_2015Oct10-FINAL1.pdf. Accessed April 22, 2016.

33. Metlay JP, Cohen A, Polsky D, Kimmel SE, Koppel R, Hennessy S. Medication safety in older adults: home-based practice patterns. J Am Geriatr Soc. 2005;53(6):976-82 